\title{
Perspetiva Ciência, Tecnologia, Sociedade, Ambiente (CTSA) nos manuais escolares portugueses de Ciências Naturais do $6^{\circ}$ ano de escolaridade
}

\section{Perspective Environment, Science, Technology, Society (ESTS) in school textbooks of Natural Sciences of the $6^{\text {th }}$ grade}

\author{
Isabel Marilia Borges Fernandes ${ }^{1}$ • https://orcid.org/0000-0003-3322-7888 \\ Delmina Maria Pires ${ }^{1}$. https://orcid.org/0000-0002-5116-8757 \\ Jaime Delgado-Iglesias ${ }^{2}$ • https://orcid.org/0000-0001-8726-6976
}

\begin{abstract}
Resumo: Tal como a nível internacional, também em Portugal é grande a importância atribuída ao manual escolar, reconhecido como um dos recursos mais utilizado por professores e alunos. Por isso, o manual escolar converteu-se num objeto de estudo de diversas investigações no âmbito da Didática das Ciências. Uma das linhas de investigação diz respeito ao enfoque Ciência-Tecnologia-Sociedade-Ambiente (CTSA), considerado por muitos investigadores como uma das tendências atuais do ensino das ciências capaz de desenvolver a literacia científica dos alunos. Neste estudo, essencialmente qualitativo, construiu-se e aplicou-se um instrumento de análise para perceber se os manuais escolares portugueses de Ciências Naturais do $6 .^{\circ}$ ano exploram os conteúdos científicos relacionando-os com a tecnologia, a sociedade e o ambiente e se apresentam atividades de índole CTSA. Os resultados mostram que o enfoque CTSA está incorporado nos manuais analisados, mas de forma insuficiente e pouco explorada.
\end{abstract}

Palavras-chave: CTSA. Manual escolar. Educação básica. Portugal. Literacia científica. Educação científica.

\begin{abstract}
At the international level, as in Portugal, there is great importance attached to the textbook, being recognized as one of the most used features by teachers and students. Therefore, the textbook has become a subject of study of various investigations into the Didactics of Science. One of the lines of investigation concerns the Environment-Science-Technology-Society (ESTS) approach, considered by many researchers as one of the current trends of teaching the sciences capable of developing the scientific literacy of students. Thus, in this essentially qualitative study we built, and applied, an analytical tool to see if the Portuguese textbooks of Natural Sciences of 6th grade explore the scientific content relating them with technology, society and the environment and present ESTS nature activities. The results show that the ESTS approach is embedded in the analyzed textbooks, but insufficiently and not fully explored.
\end{abstract}

Keywords: ESTS. Textbook. Basic education. Portugal. Scientific literacy. Science teaching.

\footnotetext{
${ }^{1}$ Instituto Politécnico de Bragança (IPB), Escola Superior de Educação (ESE), Departamento de Ciências da Natureza, Bragança, Portugal. E-mail: <isabel.fernandes@ipb.pt>.

${ }^{2}$ Universidad de Valladolid, Facultad de Educación y Trabajo Social, Departamento de Didáctica de las Ciencias Experimentales, Sociales y de la Matemática, Valladolid, España.
} 


\section{Introdução}

O manual escolar tem evoluído ao longo dos tempos. Para além de refletir as mudanças de cada época, relativas ao processo de ensino-aprendizagem, aos tipos de conhecimentos e conteúdos a aprender e às atitudes e valores a desenvolver, é também fortemente influenciado pelas mudanças políticas, económicas, sociais e culturais vivenciadas em determinada altura. Esta evolução e as influências que tem sofrido constituem-no como um recurso didático com funções educativas que foram sendo transformadas ao longo dos tempos.

Por sua vez, o ensino das ciências tem vindo a ser dominado pelo manual escolar, sendo um dos recursos mais frequentemente utilizado na prática pedagógica (LÓPEZ-VALENTÍN; GUERRA-RAMOS, 2013; MANSOUR, 2007; MORRIS, 2014; SANTOS, 2001, 2004). A importância que os principais intervenientes no contexto educativo atribuem ao manual escolar é incontestável. Os professores usam-no como fonte de informação para a preparação das aulas e para a organização do programa, os alunos apontam-no como o recurso que mais utilizam para se prepararem para os testes e para os exames e os pais/encarregados de educação consideram a sua utilização fundamental, tanto na sala de aula como fora dela (CARVALHO; FADIGAS, 2009; NUNES, 2013; VISEU; MORGADO, 2010).

Por se tratar de um recurso de grande importância no processo de ensino-aprendizagem, o manual escolar converteu-se num objeto de estudo de diversas investigações, nomeadamente, no âmbito da Didática das Ciências. Uma dessas linhas de investigação diz respeito ao enfoque CTS (Ciência-Tecnologia-Sociedade) considerado por muitos investigadores (AIKENHEAD, 2009; FERNANDES, 2011; FERNANDES; PIRES, 2013; OCCELLI; VALEIRAS, 2013; OSBORNE, 2011; TENREIRO-VIEIRA; VIEIRA, 2012; VÁZQUEZ; MANASSERO, 2012) como uma das tendências mais atuais e atrativas do ensino das ciências, capaz de desenvolver nos alunos capacidades de elevado nível de abstração que lhes permitem envolver-se criticamente com a ciência do, e no, seu dia a dia.

A inclusão do conceito de Ambiente, com a qual concordamos e que adotamos, tende a tornar mais explícitas as interações entre diferentes dimensões da Ciência. Ao realçar a problemática das questões ambientais e da qualidade de vida, esta nova ênfase, Ciência-Tecnologia-Sociedade-Ambiente (CTSA), contribui para uma imagem mais completa e integrada da Ciência, e é considerada por alguns autores (GIL; VILCHES, 2004; VILCHES; GIL, 2010) como uma resposta à situação de emergência planetária com contributos para uma nova ordem socio-ambiental para se assentarem as bases de um futuro sustentável.

\section{Propósitos da educação CTSA}

A grande finalidade da educação em Ciências numa perspetiva CTSA (Ciência-Tecnologia-Sociedade-Ambiente) é dar da Ciência uma visão integrada, relacionando-a com a Tecnologia e evidenciando os impactos que estas têm na Sociedade e no Ambiente, bem como a influência que a Sociedade/Ambiente tem no desenvolvimento da Ciência e da Tecnologia. Atualmente, a Ciência e a Tecnologia formam um conjunto de realidades tão vinculadas que se torna difícil separa-las, e que está presente em quase todos os aspetos da nossa vida. Desta forma, a realidade da Ciência atual deve ser vista como a integração da Ciência e da Tecnologia, Tecnociência (que utiliza elementos quer da Ciência, quer da Tecnologia) e, por isso, a educação científica deve 
aproximar-se de uma visão interativa entre ambas, o que equivale a uma visão mais real da Ciência (VÁZQUEZ; MANASSERO, 2012). Neste sentido, a educação CTSA procura compreender a dimensão social da Ciência e da Tecnologia, tanto no que diz respeito aos fatores de natureza social, política ou económica que influenciam a mudança científico-tecnológica, como no que concerne às repercussões éticas, ambientais ou culturais dessa mudança. Pretende ser uma aposta para uma educação científica orientada para a cidadania promovendo a responsabilidade social na tomada de decisões coletivas relacionadas com a Ciência e a Tecnologia, quer se trate de aspetos positivos, quer se trate de aspetos negativos (AIKENHEAD, 2009; FERNANDES; PIRES, 2013; VÁZQUEZ; MANASSERO, 2012; VILCHES; GIL, 2010).

Assim, partilhamos da opinião de diversos autores (AIKENHEAD, 2009; FERNANDES, 2011; FERNANDES; PIRES, 2013; OSBORNE, 2011; TENREIRO-VIEIRA; VIEIRA, 2012; VÁZQUEZ; MANASSERO, 2012) que apontam vários argumentos a favor da educação em Ciências segundo a perspetiva CTSA. Os alunos tiram proveito da educação CTSA caso tenham um ensino com uma orientação clara, contextualizada e significativa, que lhes permita ter uma visão integradora da natureza da Ciência e da Tecnologia e das relações mútuas que estabelecem entre si e com a Sociedade e o Ambiente. Trata-se de uma perspetiva de ensino capaz de promover o pensamento crítico e a indagação e a argumentação científica, bem como a capacidade de raciocínio e de resolução de problemas, em suma, a literacia científica dos alunos. Trata-se de possibilitar aos alunos uma educação em ciências mais contextualizada e capaz de os dotar de competências para agir e interatuar com o meio que os rodeia, bem como para tomarem decisões informadas e conscientes necessárias à resolução de problemas do quotidiano, isto é, permite formar os alunos em futuros cidadãos capazes de tomares decisões informadas cientifica e tecnologicamente acerca de questões (pessoais, profissionais e sociais) que podem influenciar ou condicionar o seu modo de vida e que são necessárias para agir de forma democrática e responsável, e de compreender os desafios sociais da Ciência e das interações recíprocas que tem com a Tecnologia, a Sociedade e o Ambiente. Trata-se de ser capaz de avaliar os impactos, quer positivos, quer negativos, da Ciência e da Tecnologia nos contextos pessoais e sociais quotidianos, nomeadamente, em questões sócio científicas que envolvam debates éticos e sociais. Em suma, é necessário, por isso, que o ensino das Ciências possibilite o desenvolvimento nos alunos não só de competências cognitivas, mas também de competências de cidadania, de atitudes e normas de conduta responsáveis, que lhes permitam tornarem-se cidadãos intervenientes ativos no mundo que os rodeia, conscientes e conhecedores dos seus direitos e deveres, e isso pode ser alcançado através da abordagem de ensino das Ciências com orientação CTSA. Esta forma de ensinar Ciências requere a compreensão, tanto da Ciência, na qual se incluem os tradicionais conhecimentos sobre os conteúdos científicos, assim como sobre os princípios e os processos da Ciência, como a compreensão sobre a Ciência, ou seja, como se constrói, como funciona e como se relaciona com a Tecnologia, a Sociedade e o Ambiente, bem como se validam e se aplicam os seus conhecimentos na compreensão do mundo atual. Tudo isto contribui para o desenvolvimento pessoal e social do indivíduo (AIKENHEAD, 2009; VÁZQUEZ; MANASSERO, 2012, 2016; VILCHES; GIL, 2010).

Deste modo a abordagem CTSA opõe-se a um ensino da ciência tradicional e permite adequar os conteúdos programáticos a uma nova compreensão da ciência, mais real e mais dinâmica e, ao mesmo tempo, menos dogmática e menos neutra, refletindo as relações e interações Ciência, Tecnologia, Sociedade e Ambiente. 
Mas para fomentar a educação CTSA no ensino das Ciências, capaz de promover nos alunos as competências e capacidades atrás referidas, por um lado, é necessário que os professores sejam capazes de implementar aulas com enfoque CTSA. Por outro lado, torna-se imprescindível que os manuais escolares, que orientam a atuação dos professores, reflitam com claridade a abordagem CTSA, quer ao nível da informação que disponibilizam, quer ao nível das atividades que propõem, dando sugestões aos professores para implementar esta perspetiva de ensino de forma adequada.

Porém, apesar da variada investigação que tem mostrado as potencialidades do enfoque CTSA no ensino das ciências, esta abordagem ainda não é suficientemente considerada pelos professores (RODRIGUES; VIEIRA, 2012; VÁZQUEZ; MANASSERO, 2016; VÁZQUEZ et al., 2012), nem claramente integrada nos manuais escolares, sem que as relações que se estabelecem entre a ciência, a tecnologia, a sociedade e o ambiente sejam devidamente realçadas e explicitadas (FERNANDES, 2011; FERNANDES; PIRES, 2013; OCCELLI; VALEIRAS, 2013; VÁZQUEZ; MANASSERO, 2012).

Relativamente aos professores, a investigação empírica tem vindo a demostrar que não possuem uma adequada compreensão da Ciência, do modo de proceder da Ciência ou, ainda, das inter-relações dos conteúdos CTSA. A maioria dos professores revela crenças tradicionais, positivistas e idealistas sobre a natureza da Ciência (RODRIGUES; VIEIRA, 2012; VÁZQUEZ; MANASSERO, 2016; VÁZQUEZ et al., 2012), o que acrescenta uma grande responsabilidade, e um longo caminho a percorrer, pela formação de professores, inicial e contínua, no sentido da desejada educação CTSA.

Relativamente aos manuais escolares, são vários os autores (FERNANDES, 2011; FERNANDES; PIRES, 2013; OCCELLI; VALEIRAS, 2013; VÁZQUEZ; MANASSERO, 2012) que apontam que estes não valorizam questões relacionadas com a história da Ciência nem dos aspetos filosóficos e epistemológicos e, quando porventura estas questões são incluídas, apresentam-se de forma descontextualizada. A este respeito, Fernandes (2011) e Fernandes e Pires (2013) desenvolveram trabalhos de investigação cujos objetivos procuraram perceber se os manuais escolares portugueses de Ciências do $5^{\circ}$ ano de escolaridade incorporavam a perspetiva CTSA e de que forma a incorporavam, no âmbito do discurso/informação facultada e das atividades de ensino/aprendizagem sugeridas. Os resultados destas pesquisas mostraram que a incorporação desta perspetiva ainda é pouco considerada. Podemos dizer que esta abordagem está presente, mas nem por isso reflete uma adequada Educação em Ciências com orientação CTSA, uma vez que, nem sempre são estabelecidas relações entre a Ciência, a Tecnologia, a Sociedade e o Ambiente, e quando o são, nem sempre essas relações são suficientemente evidenciadas para se tornarem claras para professores e alunos. Estes resultados são coerentes com os estudos de outros autores (OCCELLI; VALEIRAS, 2013; VÁZQUEZ; MANASSERO, 2012) que referem que nos manuais de Ciências prevalecem detalhes científicos sem reconstrução histórica de dados e em que são omissos, quer o contexto em que se desenvolve o trabalho científico, quer interpretações alternativas que poderiam dar lugar a temas controversos e conflitos, resultando no aparecimento de conceções ingénuas e pouco explícitas sobre a natureza da Ciência que não contribuem para promover uma adequada educação CTSA. 


\section{Objetivo}

Assim, no contexto desta problemática, as conclusões das investigações de Fernandes (2011) e Fernandes e Pires (2013) despertaram um interesse crescente pelo tema e, por isso, procurou-se desenvolver uma investigação que pudesse dar continuidade a este trabalho. Uma vez que a etapa do $2 .^{\circ}$ Ciclo do Ensino Básico (10-12 anos) em Portugal compreende o $5 .^{\circ} \mathrm{e}$ o $6 .^{\circ}$ ano de escolaridade, desenvolveu-se um estudo que permite-se perceber se esta problemática também está patente em manuais escolares de ciências do $6^{\circ}$ ano de escolaridade que corresponde ao ano seguinte desta etapa de ensino.

Deste modo, foi intenção do estudo desenvolvido, e o seu grande objetivo, perceber se os manuais escolares de Ciências Naturais do $6 .^{\circ}$ ano de escolaridade exploram os conteúdos científicos relacionando-os com a tecnologia, a sociedade e o ambiente, e se apresentam atividades que apelem para o estabelecimento dessas relações. Fez-se uma análise interpretativa aos manuais escolares em função das questões que se seguem:

1) Os manuais escolares portugueses de Ciências Naturais de $6 .^{\circ}$ ano de escolaridade incorporam a perspetiva CTSA?

2) Os manuais escolares portugueses de Ciências Naturais de $6 .^{\circ}$ ano de escolaridade exploram os conteúdos científicos, interligando a ciência com a tecnologia com a qual se relaciona, e com o impacto que estas têm na sociedade e no ambiente, realçando quer os impactos positivos, quer os impactos negativos?

3) Os manuais escolares portugueses de Ciências Naturais de $6 .^{\circ}$ ano de escolaridade apresentam sugestões de atividades para abordar os conteúdos com a perspetiva CTSA?

4) As relações que se estabelecem entre a ciência, a tecnologia, a sociedade e o ambiente apresentam-se claramente expressas/percetíveis nos manuais escolares envolvidos no estudo?

\section{Procedimentos investigativos}

Nesta investigação, de índole predominantemente qualitativa, para a recolha de dados acerca da forma como o enfoque CTSA é contemplado e abordado nos manuais escolares de Ciências Naturais, foi utilizada como técnica a análise documental de tipo descritiva e interpretativa.

Num total de nove manuais de $6 .^{\circ}$ ano de escolaridade disponíveis, foram selecionados seis representativos das diferentes editoras com mais venda no mercado português, identificados como $6 .{ }^{\circ} \mathrm{MP} 1,6 .{ }^{\circ} \mathrm{MP} 2,[\ldots], 6 .{ }^{\circ} \mathrm{MP} 6$. Embora recentes, e em utilização, estes manuais foram editados antes da última reforma educativa ocorrida em Portugal (PORTUGAL, 2012). Porém, as alterações introduzidas pela nova reforma curricular não afetam a análise efetuada (nem os resultados obtidos), uma vez que não foram alterados os conteúdos científicos dos manuais.

Para a recolha de dados foi utilizado um instrumento de análise, construído tendo como base Alves (2005), e já aplicado numa investigação anterior sobre manuais escolares do 5. ${ }^{\circ}$ ano de escolaridade (FERNANDES, 2011). O instrumento foi revisto tendo em conta os questionários Views on Science-Technology-Society (VOSTS) (AIKENHEAD; RYAN, 1992), e Cuestionário de Opiniones sobre Ciencia, Tecnología y Sociedad (COCTS) (MANASSERO; VÁZQUEZ; ACEVEDO, 2001). O instrumento de análise construído contempla, nos seus vários indicadores, todos os tópicos sugeridos pelos questionários VOSTS e COCTS e, para 
além disso, acrescentaram-se aspetos relacionados com a problemática ambiental e a com a qualidade de vida.

Para assegurar a coerência entre o instrumento concebido e a análise pretendida, garantindo a sua validade e fidelidade, recorreu-se a um painel de juízes especialistas na área da Didática das Ciências.

Na sua versão final, o instrumento de análise dos manuais escolares utilizado considera duas dimensões de análise, que representam os elementos de concretização do processo de ensino-aprendizagem, o Discurso/Informação facultada (dimensão A), com nove indicadores (A1; A2, ..., A9), e as Atividades de ensino/ aprendizagem propostas (dimensão B), com quatro indicadores (B1; B2, ..., B4). Os vários indicadores que compõem as duas dimensões, e que operacionalizam as inter-relações CTSA, podem ser observados no Quadro 1.

Quadro 1. Instrumento de análise de manuais escolares

\begin{tabular}{|l|l|}
\hline & \multicolumn{1}{|c|}{ Indicadores } \\
\hline & $\begin{array}{l}\text { A1- Explora os tópicos de ciências em função da utilidade social. } \\
\text { A2- Mostra que o trabalho dos cientistas é, muitas vezes, influenciado por pressões sociais, } \\
\text { políticas, religiosas e económicas. }\end{array}$ \\
\hline A3- No que concerne à Ciência e à Tecnologia, encoraja os alunos a: (i) levantar ideias, \\
autónoma e voluntariamente; (ii) mudar as suas opiniões; (iii) Fazer analogias; (iv) Dar \\
explicações.
\end{tabular}

Fonte: elaborado pelos autores. 
Dada a natureza essencialmente qualitativa desta investigação, para organizar e interpretar o material recolhido optou-se, como já referimos, pela análise de conteúdo como técnica de tratamento de dados, que exige que os dados recolhidos se organizem e sintetizem para que se possam interpretar à luz do quadro teórico estabelecido e dar resposta às questões e objetivos de investigação pré-definidos.

Autores como Bardin (2009) e Coutinho (2011) consideram que a análise de conteúdo é uma técnica de tratamento de dados adequada num estudo qualitativo pois permite fazer inferências, através da identificação sistemática e objetiva das características específicas da mensagem, de modo a caracterizar a ocorrência de palavras ou frases (unidades de analise/episódios), que possibilitem uma posterior comparação. $\mathrm{O}$ investigador procura regularidades e faz inferências a partir dessas regularidades. Durante este processo identificam-se caraterísticas específicas das mensagens/discursos analisados, efetuam-se deduções lógicas e justificadas a respeito dessas mensagens e faz-se a sua interpretação.

A finalidade da análise de conteúdo consiste em efetuar inferências, com base numa lógica explicitada, sobre mensagens cujas características foram inventariadas e sistematizadas (BOGDAN; BIKLEN, 1994).

Assim, facilitar o processo de análise e o tratamento de dados elaborou-se uma síntese descritiva de inferências, num confronto contínuo com o quadro teórico previamente delineado.

Deste modo, a análise dos manuais escolares portugueses de Ciências Naturais do 6. ${ }^{\circ}$ ano de escolaridade teve início com uma leitura geral dos mesmos que permitiu definir e identificar unidades/episódios de análise que evidenciassem as ideias dos indicadores de cada uma das dimensões consideradas no instrumento de análise. Posteriormente, estas unidades de análise foram estudadas criteriosamente de modo a perceber a sua coerência com os indicadores das dimensões do instrumento de análise (dimensão A- Discurso/Informação facultada, e dimensão B- Atividades de ensino/ aprendizagem propostas).

\section{Resultados}

Uma primeira análise permitiu-nos compreender que o enfoque, a perspetiva CTSA de ensino das ciências está presente em todos os manuais analisados, embora de forma diferente, como se pode constatar no quadro 2 .

Quadro 2. Incorporação da perspetiva CTSA nos manuais escolares de Ciências do $6 .^{\circ}$ ano

\begin{tabular}{|c|c|c|c|c|c|c|c|}
\hline \multirow{2}{*}{\multicolumn{2}{|c|}{$\begin{array}{c}\text { Incorporação da Perspetiva CTSA } \\
\text { Indicadores }\end{array}$}} & \multicolumn{6}{|c|}{ Manuais escolares de ciências $\left(6^{\circ}\right.$ ano $)$} \\
\hline & & $6^{\circ}{ }^{\circ} \mathrm{MP1}$ & $6 .^{\circ} \mathrm{MP2}$ & $6 .^{\circ} \mathrm{MP3}$ & $6 .^{\circ} \mathrm{MP} 4$ & $6^{\circ}{ }^{\circ} \mathrm{MP5}$ & $6 .^{\circ} \mathrm{MP6}$ \\
\hline \multirow{2}{*}{ 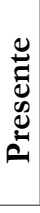 } & $\begin{array}{l}\text { De forma integrada nos conteúdos e } \\
\text { nas atividades, ao longo das diferentes } \\
\text { unidades temáticas. }\end{array}$ & $\mathrm{x}$ & $\mathrm{x}$ & & & & $\mathrm{x}$ \\
\hline & $\begin{array}{l}\text { Em secções próprias, com denominação } \\
\text { CTSA ou outras designações. }\end{array}$ & $\mathrm{x}$ & $\mathrm{x}$ & $\mathrm{x}$ & $\mathrm{x}$ & $\mathrm{x}$ & $\mathrm{x}$ \\
\hline & Ausente & --- & --- & --- & --- & --- & --- \\
\hline
\end{tabular}

Fonte: elaborado pelos autores. 
Os resultados do quadro 2 mostram que nos manuais $6 .^{\circ} \mathrm{MP} 1,6{ }^{\circ} \mathrm{MP} 2$ e $6{ }^{\circ} \mathrm{MP} 6$, a perspetiva CTSA aparece integrada nos conteúdos didáticos explorados no manual e nas propostas de atividades ao longo das unidades temáticas e, ainda, em secções próprias, com denominação CTSA ou outras designações. Nos manuais $6 .^{\circ} \mathrm{MP} 3,6{ }^{\circ} \mathrm{MP} 4$ e $6 .^{\circ} \mathrm{MP} 5$, a perspetiva CTSA apenas aparece contemplada em secções denominadas CTSA ou outras.

Depois de percebermos que a perspetiva CTSA estava presente em todos os manuais escolares de Ciências Naturais de $6 .^{\circ}$ ano, a análise seguinte procurou compreender a enfâse dessa presença e a amplitude da integração por dimensão de análise, discurso e atividades. $\mathrm{Ou}$ seja, fez-se a identificação de episódios reveladores das interações CTSA, quer no discurso/na informação que os manuais facultam (dimensão A), quer nas atividades de ensino/aprendizagem que propõem (dimensão B). Esses resultados apresentam-se no quadro 3.

Quadro 3. Número de episódios CTSA, por dimensão de análise, presentes nos manuais escolares de ciências de $6 .^{\circ}$ ano

\begin{tabular}{|r|c|}
\hline \multicolumn{1}{|c|}{ Dimensão } & MEP \\
\hline A - Discurso/Informação facultada & 105 \\
\hline B - Atividades de ensino/aprendizagem propostas & 30 \\
\hline Total & 135 \\
\hline
\end{tabular}

Fonte: elaborado pelos autores.

O quadro 3 refere a existência de 135 episódios, na totalidade dos seis manuais escolares analisados, onde é possível identificar relações e interações CTSA. É no discurso, ou seja, na informação que os manuais facultam onde o enfoque CTSA está mais representado, com 105 episódios, e menos representado nas atividades de ensino/aprendizagem que propõem (dimensão B), com apenas 30 episódios. Estes resultados parecem indicar que, de uma maneira geral, os autores dos manuais escolares, embora estejam cientes das relações CTSA, pois introduzemnas na informação que disponibilizam, têm alguma dificuldade em propor atividades CTSA.

Considerem-se os exemplos que se seguem, muito presentes na generalidade dos manuais analisados: um exemplo refere-se ao texto identificado num dos manuais escolares ( $\left.6 .^{\circ} \mathrm{MP} 2\right)$ que dá exemplos de técnicas aplicadas nos processos de conservação dos alimentos (relação ciência-tecnologia-sociedade) e enumera algumas como a fumagem, a secagem e a aplicação de conservantes tradicionais, que são ilustradas com imagens explicativas; noutro exemplo, identificado no manual escolar $6 .^{\circ} \mathrm{MP} 3$, os alunos são informados que o desaparecimento das florestas devido à ação humana contribui para o aumento de dióxido de carbono na atmosfera que, por sua vez, provoca o efeito de estufa (relação Sociedade-Ambiente).

Em relação às atividades, são escassas, por exemplo, as situações em que os alunos podem explorar e avaliar relações CTSA, e até mesmo esquecidas as atividades que interferem na vida pessoal dos alunos ou que levem ao seu envolvimento em projetos onde essas relações/ interações se manifestam (como sejam, por exemplo, recolha de dados e discussão argumentada face às consequências da ação humana na poluição de um rio da região do aluno ou pesquisa acerca da implementação de um aterro sanitário perto de um curso de água). 
Além disso, da análise efetuada, foi possível perceber que existe alguma discrepância no grau de explicitação dos episódios/unidades de análise identificadas nos diferentes manuais escolares de Ciências Naturais estudados. Ou seja, as relações entre a ciência, a tecnologia, a sociedade e o ambiente nem sempre estão claramente expressas e evidenciadas.

Assim, foi necessário efetuar uma análise muito pormenorizada, na qual importava distinguir episódios explícitos de episódios implícitos. Esta distinção é fundamental, pois os episódios implícitos, ainda que não façam sentido aos alunos, podem ser muito importante para um professor com formação e/ou conhecimentos no âmbito desta temática ou, simplesmente, com sensibilidade para as relações CTSA, que os pode utilizar e dar-lhes sentido, contribuindo assim para uma efetiva educação científica. Quando os pressupostos assumidos nos indicadores estão presentes, de forma clara e precisa, nos episódios identificados, consideraram-se episódios explícitos. Quando os pressupostos assumidos nos indicadores não estão claramente expressos nos episódios identificados, mas há uma frase, uma expressão ou uma imagem que podem servir de base para o seu desenvolvimento, foram considerados episódios implícitos.

Como exemplo de episódio explícito do indicador A4 (Permite desenvolver uma atitude crítica e fundamentada cientificamente perante problemas sociais e ambientais), consideramos um texto identificado num manual escolar ( $\left.6 .{ }^{\circ} \mathrm{MP} 6\right)$ que refere que nas últimas décadas tem-se assistido a um grande progresso da Ciência e da Tecnologia, porém, esta evolução, a par do aumento da população mundial, tem provocado uma série de consequências ambientais desfavoráveis, tais como incêndios florestais, pulverizações com pesticidas, industrias e veículos automóveis que contribuem para a contaminação do ar. Este texto transmite a ideia de que os avanços científicos e tecnológicos, bem como a Sociedade são responsáveis pelas consequências ambientais (relação Ciência-Tecnologia-Sociedade-Ambiente).

Ao contrário do anterior, como exemplo de episódio implícito, apresentamos um texto identificado no manual $6 .^{\circ} \mathrm{MP} 1$, também relacionado com o indicador A4, que refere que devido ao crescimento da indústria de pasta de celulose nos últimos anos a área florestal ocupada pelo eucalipto tem aumentado. O fabrico de papel é importante para a economia do nosso país, mas os especialistas discutem se este aumento é benéfico para a floresta portuguesa.

O texto apresenta informação que permite desenvolver uma atitude crítica e fundamentada cientificamente perante problemas sociais (crescimento da economia do nosso país) e ambientais (empobrecimento dos solos da floresta portuguesa devido ao eucalipto), embora o faça de forma implícita e pouco clara para os alunos. A exploração do texto permite que aluno compreenda que o crescimento da indústria de pasta de papel depende da produção do eucalipto (relação Tecnologia-Ambiente). Por outro lado, também permite que o aluno perceba que o fabrico de papel é importante para a economia (relação Ambiente-Sociedade). Porém, o texto não esclarece que é devido às características do eucalipto, que empobrece o solo, que os especialistas discutem acerca do aumento de produção de eucalipto, que sendo tão importante para a indústria e para a economia, não é benéfico para a floresta portuguesa (relação CiênciaTecnologia-Sociedade-Ambiente). Consideramos que da interpretação e discussão do texto é possível desenvolver uma atitude crítica e fundamentada cientificamente perante questões tecnológicas e ambientais, ajudando os alunos a tomar uma posição fundamentada cientificamente. Mas para que isso seja viável, é preciso que o professor seja conhecedor das relações CTSA e seja sensível para esta temática. 
Para uma fácil perceção do que acabamos de referir, apresentamos em gráfico (figura 1) o número de episódios explícitos (E) e implícitos (I) identificados por dimensão nos manuais escolares portugueses de Ciências Naturais do $6 .^{\circ}$ ano de escolaridade.

Pela observação do gráfico da figura 1 constatamos que os manuais portugueses de $6^{\circ}{ }^{\circ}$ ano, no que diz respeito às relações CTSA, são mais explícitos no discurso/informação que facultam (dimensão A) do que nas atividades que propõem (dimensão B). Se excetuarmos os manuais $6 .^{\circ} \mathrm{MP} 2$ e $6 .^{\circ} \mathrm{MP} 6$, com episódios explícitos, e o $6{ }^{\circ} \mathrm{MP} 3$, com apenas um episódio explícito, relacionado com a dimensão $\mathrm{B}$, todos os outros apenas apresentam episódios implícitos relacionados com esta dimensão. São os manuais $6 .^{\circ} \mathrm{MP} 1$ e $6 .^{\circ} \mathrm{MP} 2$ os que mais utilizam um discurso/informação que promove a Educação em Ciências segundo a perspetiva CTSA, embora, no caso do manual $6 .^{\circ} \mathrm{MP} 2$, muitos episódios se apresentem na forma implícita. Realçamos o manual 6. ${ }^{\circ} \mathrm{MP} 6$, em que o número de episódios CTSA, apesar de não ser muito apreciável (24 episódios), mas há algum equilíbrio entre os episódios explícitos e implícitos, no que diz respeito ao discurso facultado e onde há mais sugestões de propostas de atividades com explicitação de relações CTSA.

Figura 1. Número de episódios explícitos e implícitos por dimensão, nos manuais escolares portugueses de Ciências de $6 .^{\circ}$ ano de escolaridade

\section{Episódios por dimensão nos manuais portugueses de $6^{\circ}$ ano de Ciências}

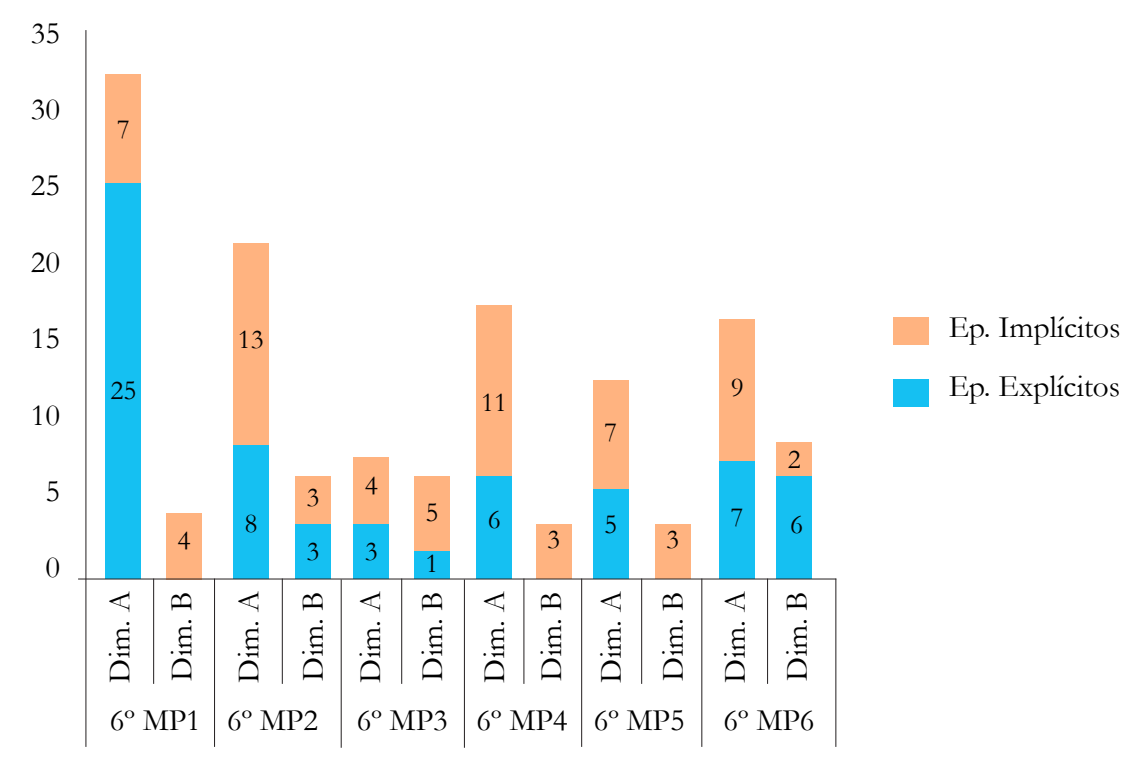

Fonte: elaborado pelos autores. 
Na tabela 1 apresenta-se uma visão de conjunto de todos os dados obtidos pela análise dos manuais escolares portugueses de Ciências Naturais do $6 .^{\circ}$ ano de escolaridades, no que diz respeito à perspetiva CTSA. É possível apreciar uma visão global do número de episódios explícitos (E) e implícitos (I) identificados e discriminados por manual e em função dos indicadores/dimensões de análise.

Os resultados apresentados mostram que o manual que contempla mais episódios é o manual $6 .^{\circ} \mathrm{MP} 1$, com um número razoável de episódios, 36 no total, e a maioria explícitos (25 explícitos e 11 implícitos), seguido do manual $6 .^{\circ} \mathrm{MP} 2$, também com um número razoável de episódios identificados, 27 no total, mas com mais episódios implícitos do que explícitos (11 explícitos e 16 implícitos) e do manual 6. ${ }^{\circ} \mathrm{MP} 6$, com 24 episódios (13 explícitos e 11 implícitos). Segue-se o manual $6 .^{\circ} \mathrm{MP} 4$, com 20 episódios (6 explícitos e 14 implícitos) e, por último, o manual $6{ }^{\circ} \mathrm{MP} 5$, com 15 episódios (5 explícitos e 10 implícitos) e o manual $6{ }^{\circ} \mathrm{MP} 3$, com apenas 13 episódios e a maioria implícitos (4 explícitos e 9 implícitos). Em síntese, à exceção dos manuais escolares $6 .^{\circ} \mathrm{MP} 1$ e $6 .^{\circ} \mathrm{MP} 6$, em todos os outros, o número de episódios implícitos é superior ao número de episódios explícitos.

Tabela 1. Número de episódios, explícitos e implícitos, identificados nos manuais escolares de Ciências Naturais, do $6 .^{\circ}$ ano de escolaridade

\begin{tabular}{|c|c|c|c|c|c|c|c|c|c|c|c|c|c|c|c|c|}
\hline \multicolumn{17}{|c|}{ Indicadores $(n=13)$} \\
\hline Manual & Episódio & A1 & A2 & A3 & A4 & A5 & A6 & A7 & A8 & A9 & B1 & B2 & B3 & B4 & $\begin{array}{r}\text { Total episó } \\
\text { por mant }\end{array}$ & \\
\hline \multirow{3}{*}{ 6. ${ }^{\circ} \mathrm{MP} 1$} & $\mathrm{E}$ & 3 & 0 & 1 & 6 & 2 & 5 & 0 & 1 & 7 & 0 & 0 & 0 & 0 & 25 & \\
\hline & $\mathrm{I}$ & 0 & 0 & 0 & 3 & 4 & 0 & 0 & 0 & 0 & 0 & 4 & 0 & 0 & 11 & \multirow[t]{2}{*}{36} \\
\hline & $\mathrm{E}$ & 1 & 0 & 0 & 2 & 2 & 1 & 0 & 1 & 1 & 0 & 2 & 0 & 1 & 11 & \\
\hline \multirow[t]{2}{*}{$6 .^{\circ} \mathrm{MP} 2$} & I & 2 & 0 & 0 & 2 & 4 & 0 & 2 & 1 & 2 & 0 & 3 & 0 & 0 & 16 & \multirow[t]{2}{*}{27} \\
\hline & $\mathrm{E}$ & 0 & 0 & 0 & 2 & 0 & 1 & 0 & 0 & 0 & 0 & 1 & 0 & 0 & 4 & \\
\hline \multirow[t]{2}{*}{ 6. ${ }^{\circ} \mathrm{MP3}$} & I & 2 & 0 & 0 & 2 & 0 & 0 & 0 & 0 & 0 & 0 & 5 & 0 & 0 & 9 & \multirow[t]{2}{*}{13} \\
\hline & $\mathrm{E}$ & 0 & 0 & 0 & 2 & 1 & 0 & 2 & 0 & 1 & 0 & 0 & 0 & 0 & 6 & \\
\hline \multirow[t]{2}{*}{ 6. ${ }^{\circ} \mathrm{MP} 4$} & I & 2 & 2 & 0 & 1 & 1 & 0 & 0 & 1 & 4 & 0 & 3 & 0 & 0 & 14 & \multirow[t]{2}{*}{20} \\
\hline & $\mathrm{E}$ & 0 & 0 & 0 & 1 & 1 & 1 & 0 & 1 & 1 & 0 & 0 & 0 & 0 & 5 & \\
\hline \multirow[t]{2}{*}{ 6. ${ }^{\circ} \mathrm{MP5}$} & I & 1 & 3 & 0 & 1 & 2 & 0 & 0 & 0 & 0 & 0 & 3 & 0 & 0 & 10 & \multirow[t]{2}{*}{15} \\
\hline & $\mathrm{E}$ & 2 & 0 & 0 & 2 & 1 & 1 & 0 & 0 & 1 & 0 & 5 & 0 & 1 & 13 & \\
\hline $6 .^{\circ} \mathrm{MP} 6$ & I & 1 & 2 & 0 & 2 & 2 & 1 & 0 & 0 & 1 & 0 & 2 & 0 & 0 & 11 & 24 \\
\hline Total & $\mathrm{E}$ & 6 & 0 & 1 & 15 & 7 & 9 & 2 & 3 & 11 & 0 & 8 & 0 & 2 & & \\
\hline $\begin{array}{l}\text { episódios } \\
\text { por }\end{array}$ & $\mathrm{I}$ & 8 & 7 & 0 & 11 & 13 & 1 & 2 & 2 & 7 & 0 & 20 & 0 & 0 & \multirow{2}{*}{\multicolumn{2}{|c|}{135}} \\
\hline indicador & $\mathrm{T}$ & 14 & 7 & 1 & 26 & 20 & 10 & 4 & 5 & 18 & 0 & 28 & 0 & 2 & & \\
\hline
\end{tabular}

Fonte: elaborado pelos autores.

Assim, no conjunto dos 135 episódios identificados nos manuais analisados, apenas 64 são explícitos (E), representando 47,4\% do total de episódios identificados, e 71 são implícitos (I), representando 52,6\% dos episódios estudados. Estes resultados permitem afirmar que mais 
de metade dos episódios identificados não evidenciam, de forma clara e percetível, para os professores e para os alunos, as interações CTSA. Consideramos que o número de episódios explícitos não é suficiente para se dizer que os manuais escolares facilitam/promovem uma adequada educação CTSA. É claro que, como já referimos, um professor conhecedor da temática CTSA e/ou com sensibilidade para as interações entre a ciência, a tecnologia, a sociedade e o ambiente, pode interpretar e dar sentido às ideias dos episódios implícitos, mas isso não é suficiente, no entanto, torna ainda mais premente a necessidade de formação CTSA por parte dos professores.

Pela observação da tabela 1 é fácil de constatar, para além da desigualdade de episódios por dimensão, quer explícitos, quer implícitos, a desigualdade de episódios por indicador. Também é fácil perceber que não se verifica a ocorrência de todos os indicadores previstos no instrumento de análise. Em suma, enquanto o indicador A4 está presente em 26 episódios, o indicador A3, por exemplo, apenas foi identificado em um episódio e o indicador B4 em dois episódios. Dos 13 indicadores contemplados no instrumento de análise, há mesmo dois, os indicadores B1 e B3 em relação aos quais não foram identificados episódios.

De seguida, faremos uma análise pormenorizada dos vários episódios identificados por cada uma das dimensões de análise.

Quanto à dimensão A (Discurso/Informação facultada), como já dissemos, o indicador mais representado é o indicador A4 (Permite desenvolver uma atitude crítica e fundamentada cientificamente, perante problemas sociais e ambientais), com 26 episódios, seguido do indicador A5 (Dá exemplos de tecnologias recentes aplicadas na vivência do dia a dia), com 20 episódios, e do indicador A9 (Apresenta informação proveniente de várias áreas do saber, científico e tecnológico, que exige/fomenta a compreensão das interações CTS A, bem como o pensamento crítico), com 18 episódios. O indicador A1 (Explora os tópicos de Ciências em função da utilidade social), embora não tão representado como os três indicadores anteriores, destaca-se dos seguintes, com 14 episódios. Pensamos que a presença maioritária destes indicadores talvez se deva ao facto dos manuais escolares de Ciências Naturais, do $6 .^{\circ}$ ano de escolaridade, abordarem temas como a saúde, a alimentação, a reprodução humana, a importância das plantas para o mundo vivo e a qualidade do ar, entre outros, que são conteúdos científicos em relação aos quais é fácil abordar questões que foquem problemas de carácter social e ambiental. Ou seja, para estes temas é relativamente fácil identificar tecnologias recentes utilizadas na vivência do dia a dia, onde está presente a Ciência em função da sua utilidade social; mas esquecendo a necessidade de "encorajar os alunos a levantar ideias, autónoma e voluntariamente, a fazer analogias e a dar explicações no âmbito CTSA, (ideia prevista no indicados A3) ou a identificar diferentes realidades tecnológicas, evidenciando como elas mudam a forma de vida das pessoas e originam outras realidades sociais (ideia prevista no indicados A7), que contemplam um número reduzido de episódios. Por exemplo, o indicador A3 foi identificado apenas uma vez, num dos manuais analisados ( $\left.6{ }^{\circ} \mathrm{MP} 1\right)$ e o indicador A7, que foi identificado quatro vezes, mas apenas em dois manuais, sendo dois episódios explícitos (6. $\left.{ }^{\circ} \mathrm{MP} 4\right)$ e dois episódios implícitos $\left(6 .^{\circ} \mathrm{MP} 2\right)$.

$\mathrm{Na}$ dimensão B (Atividades de ensino/aprendizagem), como já dissemos, não se registou qualquer episódio para os indicadores B1 (Apresenta propostas que levem ao envolvimento do aluno em projetos promotores de capacidades de pensamento crítico sobre questões onde se manifestem as interações CTS A) e B3 (Propõe a realização de atividades práticas, experimentais, de laboratório, [...] para se explorar, compreender e avaliar as inter-relações CTS A, nomeadamente as que se prevê poderem vir a interferir na vida 
pessoal dos alunos e no seu futuro). O indicador mais representado é o B2 (Propõe atividades diversificadas de simulação da realidade, levando o aluno a pôr-se no lugar do outro, a resolver problemas, a realizar debates, discussões e pesquisas sobre questões onde se manifestem as interações CTS $A$, bem como o apelo explícito a capacidades de pensamento crítico), com 28 episódios, mas quase todos implícitos, apresentando o indicador B4 (Apresenta situações de aplicação ao dia a dia, dos novos conhecimentos, onde esteja presente a interação CTS $A$, no final das atividades propostas) em apenas 2 episódios, ainda que explícitos. Estes resultados parecem evidenciar alguma dificuldade dos autores dos manuais em explicitar interações CTSA, sendo essa dificuldade menos evidente no que diz respeito ao discurso, onde há mais evidências de índole CTSA, do que nas atividades. Esta ideia reforça-se ao observar o número reduzido de atividades explícitas que propõem debates, pesquisas, discussão de temas controversos, situações de aplicação ao dia a dia, etc., e, até mesmo, na ausência de atividades que levem ao envolvimento do aluno em projetos promotores de capacidades de pensamento crítico onde se manifestem as interações CTSA e atividades onde se estabeleçam relações entre o trabalho laboratorial/experimental e o "saber fazer" relacionado com aspetos práticos da vida.

\section{Conclusões}

À semelhança do que se constatou para os manuais escolares portugueses de Ciências do 5. ${ }^{\circ}$ ano de escolaridade nos estudos de Fernandes (2011) e Fernandes e Pires (2013), os resultados obtidos com este estudo mostram que a perspetiva CTSA também ainda é pouco explorada e apreciada nos manuais escolares do $6 .^{\circ}$ ano de Ciências Naturais. São raros os textos e atividades propostas que têm em consideração a natureza, a história e a epistemologia da ciência e da tecnologia, a construção do conhecimento científico, o trabalho dos cientistas e as interações CTSA. Quando o fazem, é quase sempre de forma implícita, não sendo claramente percetíveis para professores e alunos, e tendem a concentrá-los no início ou fim das unidades, em secções próprias designadas CTSA ou com outras designações e, portanto, não de forma integrada ao longo dos conteúdos científicos da unidade.

Tal como outros estudos (FERNANDES; PIRES, 2013; OCCELLI; VALEIRAS, 2013; SANTOS, 2004; VÁZQUEZ; MANASSERO, 2012), também este revela que são reduzidas as oportunidades que os manuais fornecem que permitam aos alunos darem-se conta de problemas com interesse e impacto social e de se envolverem e desenvolverem como cidadãos ativos na resolução de problemas tomando decisões conscientes e informadas sobres questões socio-ambientais. São reduzidos os textos que identificam formas de impacto da ciência e da tecnologia na sociedade e no ambiente e vice-versa, quer sejam positivos, quer sejam negativos, e que lhes reconheçam as vantagens e as limitações. De igual forma, são poucos os textos que ligam a ciência e a tecnologia a outros campos do saber e que relacionam aspetos económicos, políticos, religiosos e éticos da ciência e da tecnologia com questões pessoais, coletivas ou individuais. Ainda prevalece a ideia errónea de que a atividade científica é um ato individual, que os cientistas descobrem verdades absolutas, que a ciência é neutra e que o papel da mulher como cientista é pouco importante (FERNANDES; PIRES, 2013; OCCELLI; VALEIRAS, 2013). Relativamente às atividades sugeridas são poucas as que propõem debates, pesquisas, discussão de temas controversos, situações de aplicação ao dia a dia e que levem ao envolvimento do aluno em projetos promotores de capacidades de pensamento crítico onde se manifeste a in- 
teração CTSA. Como referem Occelli e Valeiras (2013) prevalece a falta de atividades dirigidas à indagação científica, à argumentação crítica e à interpretação de situações onde se manifeste a interação CTSA.

De acordo com estes resultados, e dada a reduzida explicitação, e exploração, das relações que se estabelecem entre a ciência, a tecnologia, a sociedade e o ambiente, conclui-se que os manuais escolares de Ciências Naturais ainda promovem pouco a educação CTSA, não a valorizando como fator essencial para a promoção da literacia científica dos alunos. Neste contexto, este estudo contribui para que se repense a construção de manuais escolares segundo a perspetiva CTSA, para que estes possam promover uma melhoria da qualidade do ensino das ciências.

\section{Referências}

AIKENHEAD, G. S. Educação científica para todos. Mangualde: Edições Pedago, 2009.

AIKENHEAD, G. S.; RYAN, A. G. The development of a new instrument: 'Views on Science-Technology-Society' (VOSTS). Science Education, New York, v. 76, n. 5, p. 477-491, 1992. Disponível em: <https://doi.org/10.1002/sce.3730760503>. Acesso em: 8 out. 2018.

ALVES, D. F. F. Manuais escolares de estudo do meio, educação CTS e pensamento crítico. 2005. 190 f. Dissertação (Mestrado em Educação em Ciências) - Universidade de Aveiro, Aveiro, 2005. Disponível em: <http://hdl.handle.net/10773/4998>. Acesso em: 4 out. 2018.

BARDIN, L. Análise de conteúdo. Lisboa: Edições 70, 2009.

BOGDAN, R.; BIKLEN, S. Investigação qualitativa em educação: uma introdução à teoria e aos métodos. Porto: Porto Editora, 1994.

CARVALHO, A.; FADIGAS, N. Os manuais escolares na relação escola-família. Porto: Observatório dos Recursos Educativos, 2009.

COUTINHO, C. P. Metodologia da investigação em ciências sociais e humanas: teoria e prática. 2. ed. Coimbra: Almedina, 2011.

FERNANDES, I. M. B. A perspectiva CTSA nos manuais escolares de ciências da natureza do $2^{\mathbf{o}}$ CEB. 2011. 124 f. Dissertação (Mestrado em Ensino de Ciências) - Escola Superior de Educação, Instituto Politécnico de Bragança, Bragança, 2011. Disponível em: $<$ http:/ / www.ore.org.pt/filesobservatorio/pdf/tesemestisabelfernandes.pdf $>$. Acesso em: 4 out. 2018.

FERNANDES, I. M.; PIRES, D. As inter-relações CTSA nos manuais escolares de ciências do $2^{\circ}$ CEB. Eduser: revista de educação, Bragança, v. 5, n. 2, p. 35-47, 2013. Disponível em: <https://www.eduser.ipb.pt/index.php/eduser/article/view/55>. Acesso em: 4 out. 2018. 
GIL, D.; VILCHES, A. Contribución de la ciencia a la cultura ciudadana. Cultura y Educación, Barcelona, v. 16, n. 3, p. 259-272, 2004. Disponível em: <https://doi. org/10.1174/1135640042360924>. Acesso em: 4 out. 2018.

LÓPEZ-VALENTÍN, D. M.; GUERRA-RAMOS, M. T. Análisis de las actividades de aprendizaje incluidas en libros de texto de ciencias naturales para educación primaria utilizados en México. Enseñanza de las Ciencias, Barcelona, v. 31, n. 2, p. 173-191, 2013. Disponível em: <https://www.raco.cat/index.php/Ensenanza/article/view/285757>. Acesso em: 4 out. 2018.

MANASSERO, M.; VÁZQUEZ, A.; ACEVEDO, J. A. Cuestionario de opiniones sobre ciencia, tecnología y sociedad (COCTS). Palma de Mallorca: Universidad de las Islas Baleares: Departamento de Psicologia, 2001.

MANSOUR, N. Challenges to STS education: implications for science teacher education. Bulletin of Science, Technology \& Society, University Park, v. 27, n. 6, p. 482-497, 2007. Disponível em: <https://doi.org/10.1177/0270467607308286>. Acesso em: 4 out. 2018.

MORRIS, H. Socioscientific issues and multidisciplinary in school science textbooks. International Journal of Science Education, London, v. 36, n. 7, p. 1137-1158, 2014. Disponível em: <https://doi.org/10.1080/09500693.2013.848493>. Acesso em: 4 out. 2018.

NUNES, C. Os manuais escolares de história e de geografia do secundário face ao desafio das tecnologias na educação. Lisboa: Universidade Lusófona de Humanidades e Tecnologias: Instituto de Educação, 2013.

OCCELLI, M.; VALEIRAS, N. Los libros de texto de ciencias como objeto de investigación: una revisión bibliográfica. Enseñanza de las Ciencias, Barcelona, v. 3, n. 2, p. 133-152, 2013. Disponível em: <https://www.raco.cat/index.php/Ensenanza/article/view/285774>. Acesso em: 4 out. 2018.

OSBORNE, J. Science education policy and its relationship with research and practice: lessons from Europe and United Kingdom. In: DEBOER, G. E. The role of public policy in k-12 science education. Charlotte: Information Age Publishing, 2011. p. 13-46.

PORTUGAL. Ministério da Educação. Despacho n. ${ }^{\circ}$ 5306/2012. Diário da República, Lisboa, n. 77, 18. abr. 2012. 2. ${ }^{a}$ série, p. 13952-13953. Disponível em: <http://www.dge.mec. pt/sites/default/files/Basico/Legislacao/despacho_5306_2012.pdf>. Acesso em: 3 out. 2018.

RODRIGUES, M. J.; VIEIRA, R. M. Programa de formação de educadoras de infância: seu contributo para a (re)construção de conceções ciência-tecnologia-sociedade. Revista Electrónica de Enseñanza de las Ciencias, Vigo, v. 3, n. 11, p. 501-520, 2012. Disponível em < http://reec.uvigo.es/volumenes/volumen11/REEC_11_3_2_ex664.pdf>. Acesso em: 1 jan 2013.

SANTOS, M. E. A cidadania na "voz" dos manuais escolares: o que temos? o que queremos? Lisboa: Livros Horizonte, 2001. 
SANTOS, M. E. Educação pela ciência e educação sobre a ciência nos manuais escolares.

Revista Brasileira de Pesquisa em Educação em Ciências, Belo Horizonte, v. 4, n. 1, p. 76-89, 2004. Disponível em: <https://seer.ufmg.br/index.php/rbpec/article/ view/2299/1698>. Acesso em: 3 out. 2018.

TENREIRO-VIEIRA, C.; VIEIRA, R. M. Co(relação) entre a literacia científica e pensamento crítico no contexto da educação em ciências com orientação CTS. In: SEMINARIO IBÉRICO, 7. e SEMINARIO IBEROAMERICANO CTS EN LA ENSEÑANZA DE LAS CIENCIAS, 3., 2012, Madrid. Memorias... Madrid: OEI, 2012.

VÁZQUEZ, A.; MANASSERO, M. A. La selección de contenidos para enseñar naturaleza de la ciencia y tecnología (parte 2): una revisión desde los currículos de ciencias y la competencia PISA. Revista Eureka sobre Enseñanza y Divulgación de las Ciencias, Cádiz, v. 9, n. 1, p. 32-53, 2012. Disponível em: <https://revistas.uca.es/index.php/eureka/ article/view/2750>. Acesso em: 3 out. 2018.

VÁZQUEZ, A.; MANASSERO, M. A. La formación del profesorado sobre temas CTS: un modelo para mejorar sus concepciones. Indagatio Didactica, Aveiro, v. 8, n. 1, p. 110-127, 2016. Disponível em: <http://revistas.ua.pt/index.php/ID/article/view/3862/3546>.

Acesso em: 3 out. 2018.

VÁZQUEZ, A. et al. La comprensión sobre la naturaleza de la ciencia del profesorado: una propuesta integral de formación desde un análisis de caso. In: ENCUENTRO DE DIDÁCTICA DE LAS CIENCIAS EXPERIMENTALES, 25., 2012, Santiago de Compostela. Actas... Santiago de Compostela, USC, 2012. p. 181-188. Disponível em: <http://apice-dce.com/wp-content/uploads/2018/08/XXV-EDCE.pdf>. Acesso em: 3 out. 2018.

VILCHES, A.; GIL, D. Educación ambiental y educación para el desarrollo sostenible: convergencias y (supuestas) divergencias. In: SEMINÁRIO IBERO-AMERICANO CIÊNCIA-TECNOLOGIA-SOCIEDADE NO ENSINO DAS CIÊNCIAS, 2. e SEMINÁRIO IBÉRICO CTS NO ENSINO DAS CIÊNCIAS, 6., 2010, Brasília. Anais... Brasília: UnB, 2010.

VISEU, F.; MORGADO, J. Manuais escolares e desprofissionalização docente: um estudo de caso com professores de matemática. In: CONGRESO INTERNACIONAL GALEGO-PORTUGUÊS DE PSICOPEDAGOXÍA, 11., 2011, La Coruña. Libro de Actas... Universidade da Coruña, 2011. p. 991-1002.

Artigo recebido em 17/08/2017. Aceito em 01/08/2018.

Contato: Instituto Politécnico de Bragança, Escola Superior de Educação, Campus de Santa Apolónia, 5301-856, Bragança, Portugal. 